\title{
XIV
}

\section{A EDUCAÇÃO NO CONTEXTO PRISIONAL FEMININO BRASILEIRO: APONTAMENTOS SOBRE OS PLANOS ESTA- DUAIS DE EDUCAÇÃO EM PRISÕES*}

\author{
Ana Cláudia Ferreira Godinho ${ }^{1}$ \\ Fabiana Rodrigues ${ }^{2}$
}

A prisão destitui a pessoa do direito de ir e vir, mas não a destitui do direito à educação. A afirmação deste direito está presente na Constituição Federal de 1988 ao reconhecer a educação como direito de todo cidadão e cidadã, em consonância com documentos internacionais, como a Declaração Universal dos Direitos Humanos e as Regras Mínimas das Nações Unidas para o Tratamento de Reclusos, também conhecidas como Regras de Mandela.

Contudo, a oferta de educação escolar e não escolar nos estabelecimentos prisionais brasileiros indica que a consolidação deste direito está bastante distante da população carcerária do país. Se consideradas as especificidades da população carcerária feminina, há, nos aspectos legais, avanços no reconhecimento das mulheres privadas de liberdade como pessoas com necessidades distintas da população carcerária masculina; porém, na organização da oferta educacional voltada para este público evidenciam-se impasses e desafios preocupantes.

Nesse contexto, o objetivo deste capítulo é analisar os avanços, impasses e desafios na garantia do direito à educação das mulheres privadas de liberdade no Brasil. Para desenvolver nossas reflexões sobre o tema, realizamos a

*DOI - 10.29388/978-65-86678-41-3-0-f.283-300

${ }^{1}$ Pós-doutora em Educação pela Universidade Federal Fluminense. Doutora em Educação pela Universidade UNISINOS. Professora da Faculdade de Educação da Universidade Federal do Rio Grande do Sul. Professora colaboradora do Programa de Pós-graduação em Educação da Universidade do Estado de Minas Gerais. Coordenadora do Grupo de Pesquisa Educação de Jovens e Adultos em espaços escolares e não escolares.

${ }^{2}$ Pós-doutora em Educação pela Universidade Federal Fluminense. Doutora em Educação pela Universidade Federal do Rio de Janeiro. Professora da Rede Estadual de Educação do Rio de Janeiro, atuando na disciplina de História no Colégio Estadual Maria Montessori na unidade prisional feminina Joaquim Ferreira de Souza. Pesquisadora de políticas públicas e de gênero na Educação de Jovens e Adultos em espaços de restrição e privação de liberdade. 
análise documental de 15 planos estaduais de educação em prisões ${ }^{3}$, elaborados em 2012 e vigentes no período de 2012 a 2014. A escolha metodológica da análise documental decorreu da necessidade de pesquisar como a normatização e a operacionalização das políticas públicas se relaciona, além de perceber como a efetivação desses direitos é reconhecida nos Planos Estaduais de Educação nas prisões. Ademais, acreditamos ser pertinente realizar reflexões sobre as mulheres, a prisão e a educação e como essas questões se entrelaçam no processo de encarceramento e na efetivação dos direitos humanos. Esse trabalho busca se somar a outros que começam a visibilizar as mulheres em espaços de privação de liberdade e a garantia de seus direitos e do respeito as suas especificidades.

\section{As mulheres privadas de liberdade: o debate internacional}

Nesta seção, abordamos alguns aspectos sócio-históricos do encarceramento das mulheres que contribuem para compreender os avanços e impasses do debate sobre direitos humanos no Brasil. Interessa-nos refletir sobre as contribuições e limitações deste debate para superar a (in)visibilidade da população prisional feminina e a dupla condenação - legal e moral - que as mulheres enfrentam ao serem julgadas por envolvimento em crimes ou atos infracionais, que consideramos desafios-chave do reconhecimento da mulher privada de liberdade como sujeito de direitos.

O debate sobre a mulher privada de liberdade internacionalmente vem se consolidando como um tema extremamente importante sobre o sistema prisional. No entanto, França (2014) indica que ainda não se constitui como um campo específico de pesquisa, o debate sobre a mulher e o crime ainda se insere no campo da criminologia geral. Para explicar a questão, a autora cita a diferença entre o quantitativo de presos homens e mulheres. Apesar do aumento significativo de mulheres encarceradas, elas ainda são um número pequeno se comparado ao dos homens. No Brasil, por exemplo, elas representam menos de $10 \%$ da população prisional.

No entanto, os dados do Departamento Penitenciário Nacional sobre as mulheres encarceradas divulgados em 2016 apontam um aumento de 656\% do número de mulheres presas entre os anos de 2000 e 2016 (BRASIL, 2016). Atualmente a taxa de aprisionamento de mulheres por 100 mil habitantes femi-

\footnotetext{
${ }^{3}$ Os planos estaduais de educação em prisões foram: Rio de Janeiro, Espírito Santo, Minas Gerais, Rio Grande do Sul, Mato Grosso, Goiás, Bahia, Alagoas, Ceará, Paiuí, Maranhão, Amazonas, Rondônia, Acre e Amapá.
} 
ninos é de 40,6, número que coloca o Brasil como o terceiro país que mais encarcera mulheres no mundo, estando atrás apenas dos Estados Unidos da América e da Tailândia (BRASIL, 2016). Esse aumento significativo no encarceramento feminino nos alerta sobre a necessidade de consolidação desse campo para pesquisa e da garantia de diferentes direitos, entre eles a educação.

A criminologia, aos poucos, começa a se dedicar a estudar a mulher, o crime e sua punição. Esse campo de estudo caminhou no sentido de reconhecer duas vertentes para explicar a delinquência feminina: uma psico-orgânica, que entende que as questões psíquicas e orgânicas próprias da mulher possibilitam comportamentos inapropriados, como a prostituição. A outra vertente relaciona o crime e a mulher ao contexto social e sua posição de submissão ao homem (ILGENFRITZ, 2009), que de alguma forma retira dessa mulher sua "culpa" ou minimiza a sua responsabilidade sobre o ato cometido.

Novos estudos, no entanto, desenvolvem outras leituras ao reconhecer o protagonismo das mulheres na produção de sua existência, na luta pela igualdade, no mercado de trabalho e no crime. Apesar de a criminologia atual reconhecer de forma mais abrangente a reflexão sobre a mulher e o crime, ainda não avançamos no conhecimento sobre as peculiaridades desse fenômeno.

O debate sobre a criminologia feminina não é o objeto desse trabalho, mas sinaliza a importância de pensarmos os diferentes aspectos da execução penal, principalmente a educação, na tentativa de atender às demandas e especificidades desse grupo de sujeitos.

Outro aspecto importante para a reflexão sobre as mulheres encarceradas é o espaço que elas ocupam para cumprir a punição, haja vista que a prisão não é pensada arquitetonicamente nem socialmente para elas, mas são espaços adaptados ou não para eles. As condições de sobrevivência das mulheres na prisão, como a maternidade, as questões higiênicas e fisiológicas e outras também importantes, não são respeitadas e garantidas devido à alocação das mulheres em espaços pensados e construídos para atender ao público masculino.

Ademais ainda temos como construção hegemônica na sociedade a ideia de que a punição deve ser cumprida em um espaço isolado e suficiente para atender a todas as demandas da vida dos sujeitos delinquentes. Sendo assim, vivemos sob o paradigma da prisão como instituição total que atua na produção de subjetividades dessas mulheres. Goffman (1999, p. 11) compreende a instituição total como estabelecimentos "de residência e trabalho onde um grande número de indivíduos com situação semelhante, separados da sociedade mais ampla por considerável período de tempo, levam uma vida fechada e for- 
malmente administrada". Com isso, todas as atividades e os diferentes aspectos da produção da existência dos sujeitos são vivenciados nesses estabelecimentos e impactam a subjetivação das identidades a partir de um processo reconhecido por Kolker (2002) como "desterritorialização" e "reterritorialização"4.

Já Goffman (1999) reconhece esse processo de subjetivação como a mortificação do eu. Ambos autores apontam que a institucionalização dos sujeitos encarcerados propicia a desterritorialização ou mortificação a partir da segregação, isolamento e desconstrução das bases/territórios culturais e comportamentais dos sujeitos aprisionados. Ademais, as prisões femininas ainda carregam em si outras formas de desterritorialização/territorialização das mulheres, uma vez que a prisão não reconhece as diferenças de gênero. São instituições "sem gênero, sem raça, sem geração".

$\mathrm{O}$ isolamento dessas mulheres acontece de modo mais efetivo e profundo no Brasil, já que o contato entre o mundo exterior e a instituição total tem como um dos pilares a manutenção dos laços familiares nos dias de visitas e, segundo o levantamento do Depen (Brasil, 2016), a média de visita por estabelecimento penal é significativamente maior nos estabelecimentos masculinos. Ou seja, as mulheres recebem menos visitas que os homens e sofrem mais com o isolamento social.

Em Foucault (2002), encontramos a ideia da prisão como uma instituição criada na Modernidade com o caráter de segregar os indivíduos e docilizar os corpos no sentido de alcançar uma potencial ressocialização. Desse modo, a prisão foi criada para substituir o suplício - como forma de castigo físico e espetáculo bizarro de tortura física - por um sistema muito mais sofisticado e complexo, baseado em controle e disciplina rígidos voltados ao remodelamento de comportamentos, valores, pensamentos, ações e mesmo os mais sutis gestos do indivíduo. Atualmente, esses propósitos entendem a educação escolar e não escolar na prisão como uma peça-chave na criação de condições para o indivíduo sair da prisão e se reinserir na sociedade com uma nova postura: obediente às leis e normas sociais, capacitado para o trabalho e disciplinado para um convívio familiar e comunitário harmoniosos.

Esses pesquisadores contribuíram para o debate sobre a instituição prisional, as condições históricas de sua criação e os aspectos políticos e culturais que a constituem em diferentes momentos e lugares em que a prisão existe. Embora não se dediquem às especificidades do encarceramento feminino, os estudos mencionados são relevantes para aprofundamento do tema.

${ }^{4}$ Guattari (1986) - desconstrução dos territórios existenciais construídos anteriormente. 
Duas concepções de prisão concorreram desde sua criação, no final do século XVIII. Uma como lugar de punição do indivíduo criminoso pelo Estado; e outra, influenciada pelo Humanismo, que atribui à prisão as funções de "ressocialização", reintegração, reinserção do indivíduo privado de liberdade na sociedade depois do cumprimento da pena. Nessa perspectiva, a criminologia moderna aponta que uma das finalidades do encarceramento é a preparação para a ressocialização dos sujeitos e que diferentes instituições da sociedade civil devem se unir a execução penal para garantir a efetivação dessa inserção dos sujeitos à sociedade, entre essas instituições destacamos a escola, a igreja, entre outros (JULIÃO, 2011). Portanto, esse tempo encarcerado serviria como um tempo de escolarização, capacitação profissional e criação das condições para que o indivíduo possa voltar para a sociedade em melhores condições de obter um trabalho, estudar, conviver com a família e a comunidade sem reincidir no crime.

Nossa defesa é de que a educação não tem função ressocializadora, docilizadora ou adestradora de ninguém. O compromisso da educação dentro ou fora da prisão é garantir um direito humano. A educação é um elemento essencial para que o ser humano tenha condições de vida dignas, nas mais distintas sociedades, e a escola é uma instituição a que as sociedades letradas têm recorrido para universalizar o acesso ao conhecimento produzido no campo da Ciência, da Cultura, da Arte e da História. Em outras palavras, concordamos com Scarfó (2009) quando afirma que a educação em prisões é necessária porque é direito, e esta justificativa é suficiente para o seu cumprimento, e mais, assevera que, a educação pública nas prisões deve

[...] ser entendida como exercício de um direito humano que aponte, não ao tratamento penitenciário, mas ao desenvolvimento integral da pessoa, para melhorar sua qualidade de vida, formar-se profissionalmente, ter acesso à cultura e dela desfrutar. (SCARFÓ, 2009, p. 110)

Também é relevante destacar que a maior parte das mulheres presas no Brasil são marcadas pela exclusão, pela pobreza, pela violência e por suas condições de gênero. A partir dos dados do Depen (INFOPEN, 2016), é possível evidenciar essa exclusão e compreender qual o grupo de mulheres são mais vulneráveis e sujeitas ao aprisionamento. Conforme o levantamento nacional, $60 \%$ das mulheres encarceradas tem entre 18 e 29 anos; 62\%, são negras; $45 \%$ não tem o ensino fundamental completo; 3\% são alfabetizadas, mas nunca tiveram acesso à educação escolar; 2 \% são analfabetas e 15\% tem o ensino fundamen- 
tal completo. Ou seja, $65 \%$ das mulheres por diferentes motivos não conseguiram permanecer nos espaços escolares e de alguma forma tiveram negado seu direito à educação, e entre essas mulheres a maior parte é negra e jovem.

É necessário e urgente refletir sobre como a normatização e a operacionalização das políticas para essas mulheres se apresentam.

\section{O reconhecimento das mulheres privadas de liberdade como sujei- tos de direitos: aspectos legais}

Reconhecer as mulheres como sujeitos de direitos remete à luta histórica dos grupos de mulheres pela garantia da igualdade de direito e do respeito as suas especificidades. Reconhecer que mulheres em situação de privação de liberdade são também sujeitos desses direitos nos inquieta no sentido de nos fazer caminhar na reflexão sobre como a normatização identifica e garante ou não esses direitos e suas especificidades.

Como já denunciamos, as mulheres são invisibilizadas e tal fato se reflete na legislação e na constituição de medidas protetivas para as privadas de liberdade. Algumas normas, leis, pareceres e convenções internacionais e nacionais já apresentam regras mínimas para o seu atendimento. Em 1994, a Convenção Interamericana para Prevenir, Punir e Erradicar a Violência contra as mulheres, aprovada pela Organização dos Estados Americanos, definiu que essas mulheres estão em situação de vulnerabilidade social. No nono artigo, o documento afirma que mulheres em privação de liberdade estão sujeitas à violência e, por isso, os estados devem promover diferentes ações, inclusive educacional, no sentido da superação da violência e na garantia dos direitos.

Nos últimos cinquenta anos, ocorreram avanços importantes no marco protetivo das mulheres, inclusive das mulheres em situação de privação de liberdade, desde o legado do Direito Internacional dos Direitos Humanos (ALERJ, 2016). O Brasil foi signatário da maior parte dos acordos e declarações sobre o tema, entre eles a Declaração Universal dos Direitos Humanos, de 1948; Convenção sobre a Eliminação de Todas as Formas de Discriminação Contra a Mulher de 1979; Convenção Americana sobre Direitos Humanos de 1969. Cabe destacar que esses tratados e declarações pouco abordam as mulheres presas, mas são importantes no processo e na luta de reconhecer que as mulheres são sujeitos de direitos e que a violência contra essas mulheres não está circunscrita a questão física, mas que abrange a violência sexual e psicológica. 
Alguns tratados internacionais versam exclusivamente ou fazem um debate mais ampliado sobre a mulher em privação de liberdade, dentre os quais destacamos as Regras Mínimas para o tratamento de Presos, texto elaborado em 1955. Esse documento reflete o contexto histórico em que foi produzido, momento em que a luta pela igualdade de direitos entre homens e mulheres ainda não tinha alcançado grande potencial na produção de leis e normas. Tanto assim que, mais de meio século se passaram e as normas foram revisitadas e atualizadas, originando as Regras de Mandela.

Em 1955, a maternidade e a gravidez eram assuntos tratados de forma aligeirada: não havia, por exemplo, a garantia do direito da criança ao acompanhamento pela mãe, já que determinava que coubesse ao estabelecimento prisional a permissão para a sua permanência nos seus primeiros meses de vida ao lado da mãe. Em outro contexto e com a luta pelo direito das mulheres mais consolidado, a revisão do documento encaminhou no sentido de observar o que seria melhor para a criança, e ficou da seguinte maneira:

Regra 9 - A decisão de permitir uma criança de ficar com seu pai ou com sua mãe na unidade prisional deve se basear no melhor Interesse da criança. Nas unidades prisionais que abrigam filhos de detentos, providências devem ser tomadas para garantir:

(a) creches internas ou externas dotadas de pessoal qualificado, onde as crianças poderão ser deixadas quando não estiverem sob o cuidado de seu pai ou sua mãe.

(b) Serviços de saúde pediátricos, incluindo triagem médica, no ingresso e monitoramento constante de seu desenvolvimento por especialistas.

2. As crianças nas unidades prisionais com seu pai ou sua mãe nunca devem ser tratadas como presos (ONU, 1955)

O documento de 1955 não menciona a educação nos espaços escolares ou não escolares para as mulheres. Já nas Regras de Mandela, a educação e a profissionalização constam como meios de garantir a reintegração dos apenados à sociedade, porém sem reconhecer a especificidade da educação escolar e não escolar para mulheres.

Os objetivos de uma sentença de encarceramento ou de medida similar restritiva de liberdade são, prioritariamente, de proteger a sociedade contra a criminalidade e de reduzir a reincidência. Tais propósitos só podem ser alcançados se o período de encarceramento for utilizado para assegurar, na medida do possível, a reintegração de tais indivíduos à sociedade 
após sua soltura, para que possam levar uma vida autossuficiente, com respeito às leis.

2. Para esse fim, as administrações prisionais e demais autoridades competentes devem oferecer educação, formação profissional e trabalho, bem como outras formas de assistência apropriadas e disponíveis, inclusive aquelas de natureza reparadora, moral, espiritual, social, esportiva e de saúde. Tais programas, atividades e serviços devem ser oferecidos em consonância com as necessidades individuais de tratamento dos presos. (BRASIL, 2016a, p. 19).

Em 2010, a Organização das Nações Unidas reconheceu a especificidades das mulheres e lançou as Regras das Nações Unidas para o tratamento de Mulheres Presas e em Medidas não Privativas de Liberdade para Mulheres Infratoras - Regras de Bangkok. Tais regras têm como premissa o aumento em todo o mundo da população de mulheres em contexto de restrição e de privação de liberdade e reconhece que as regras e o tratamento para esta parte da população precisam urgentemente atender às demandas específicas das mulheres.

Conforme a regra 1:

A fim de que o princípio de não discriminação, seja posto em prática, deve-se ter em consideração as distintas necessidades das mulheres presas na aplicação das Regras. A atenção a essas necessidades para atingir igualdade material entre os gêneros não deverá ser considerada discriminatória (BRASIL, 2016b, p. 19).

Também com o intuito de promover a não discriminação por meio da atenção às especificidades de gênero da população carcerária feminina, o Brasil elaborou a Política Nacional de Atenção às Mulheres em Situação de Privação de Liberdade e Egressas do Sistema Prisional - PNAMPE (BRASIL, 2014). Suas diretrizes e seus objetivos, em síntese, mencionam: a prevenção da violência contra a mulher privada de liberdade; o esforço intersetorial e a participação da sociedade civil para o atendimento das mulheres; a humanização das condições de atendimento e garantia dos direitos à educação, saúde, alimentação, trabalho, proteção à maternidade, entre outros; o fomento a ações voltadas para a qualificação do atendimento, inclusive da capacitação profissional, e ao levantamento de dados sobre o sistema prisional sob a perspectiva de gênero.

O documento previa como um de seus objetivos a elaboração de políticas estaduais de atenção às mulheres privadas de liberdade e egressas do sistema prisional e como primeira meta a criação de um banco de dados sobre o sistema 
prisional feminino, além da capacitação profissional e a elaboração de ações intersetoriais voltadas às especificidades de gênero do sistema prisional feminino.

A formulação tanto das regras de Bangkok quanto da PNAMPE fundamentou-se na importância da construção de outro olhar para a garantia dos direitos humanos básicos para as mulheres infratoras. No entanto, pouco se aborda sobre o processo educacional escolar ou não-escolar voltados para a superação das diversas questões que perpassam as relações de gênero nas prisões e na vida em sociedade. Ao longo do tratado, a educação se associa a questão da saúde, educação sobre as questões de doenças sexualmente transmissíveis, entre outras.

Diferentes normas brasileiras que legislam sobre a educação e sobre a execução penal versaram sobre a educação como um tratamento penitenciário. Poucos são os que asseveram uma educação voltada para a mulher. A Lei de Execução Penal, por exemplo, data de 1984 e insere a educação escolar e nãoescolar no tratamento penitenciário. Contudo, a lei ainda é tímida ao abordar a questão da mulher presa e nada apresenta sobre a educação para essas mulheres em privação de liberdade.

$\mathrm{Na}$ Constituição de 1988, a igualdade de direitos e de obrigações entre homens e mulheres está prevista. Ademais, esse documento reconhece a educação como um direito humano básico, ou seja, um direito a ser garantido para todos e todas. A educação deve proporcionar o "pleno desenvolvimento da pessoa, seu preparo para o exercício da cidadania e sua qualificação para o trabalho" (BRASIL, 1988).

Os objetivos propostos para a educação em nossa Constituição nos possibilita perceber a importância da construção de uma educação que tenha por premissa a autonomia, o reconhecimento dos sujeitos, o respeito à diversidade e a garantia da oferta da educação a todos e todas como fator importante para a construção de cidadãos e cidadãs históricos e políticos. Portanto, pensar em uma educação que contemple as questões de gênero e que construa referenciais de respeito às diferenças, que indague a violência contra as mulheres e fortaleça as potencialidades das mesmas é urgente e necessário.

A atenção para as especificidades de gênero na oferta de educação de jovens e adultos de mulheres privadas de liberdade é bem mais recente. Somente quatro décadas depois da elaboração das Regras Mínimas para o Tratamento de Reclusos, encontramos esta questão no debate preparatório à V Conferência Internacional de Educação de Adultos - Confintea, realizada em Hamburgo, em 
1997, no tema IV - "A educação de adultos, igualdade e equidade nas relações entre homens e mulheres e maior autonomia da mulher".

Um dos pontos focais é a importância de uma educação voltada para as demandas e necessidades das mulheres na construção de sua autonomia, como ferramenta para combater as práticas que não as respeitem e não as valorizem, como prática importante no combate à violência e como espaço de tomada de consciência das suas potencialidades.

Conforme já debatemos, as mulheres presas estão em vulnerabilidade social e são muitas vezes sujeitadas a violência. Com isso, a educação destacada pela V Confintea é essencial para a luta da garantia dos Direitos Humanos desses sujeitos.

O Plano Nacional de Educação de 2014 tem como uma de suas diretrizes "a superação das desigualdades educacionais, com ênfase na promoção da cidadania e na erradicação de todas as formas de discriminação" (BRASIL, 2014), ou seja, uma educação que contribua na construção da igualdade de direitos entre os diferentes, incluindo as mulheres e os homens.

Será que estamos dando conta de todas essas questões? Ou estamos mais uma vez negando um direito às mulheres que já vivenciaram o processo de exclusão e de reclusão? Como as normativas para a educação nas prisões abordam as questões de gênero? Ou não abordam?

A partir de 2006 no Seminário Nacional Educando para a Liberdade foram iniciadas as discussões sobre as diretrizes Nacionais para a oferta de educação em estabelecimento penais. Mais uma vez o reconhecimento da importância da educação para o desenvolvimento dos sujeitos está presente, porém pouco é abordado sobre a necessidade de ofertar uma educação escolar e diferentes cursos profissionalizantes que atendam as demandas das mulheres presas.

O Parecer CNE/CEB n 4 de 2010 que aprovou Diretrizes Nacionais para a oferta de educação para jovens e adultos em situação de privação de liberdade nos estabelecimentos penais (Resolução CNE/CEB n 2/2010), reconhece na educação a potencialidade de uma emancipação e descarta a ideia que assenta a educação como privilégio, corroborando as demais legislações que ratificam a educação como um direito para todos. Ademais, articula os objetivos da educação ao da segurança. Conforme descrito, é necessário e urgente "compatibilizar a lógica da segurança (de cerceamento) com a lógica da educação (de caráter emancipatório), pois ambas são convergentes quanto aos objetivos da prisão: a recuperação e a ressocialização dos presos" (BRASIL, 2010, p. 05). 
Mesmo nesse documento que direciona a oferta da educação nas unidades penais, a educação voltada para as mulheres é invisibilizada.

Essa breve exposição de alguns marcos regulatórios da educação, no contexto de privação de liberdade, corrobora o que já afirmamos e denunciamos, a mulher no espaço prisional não tem garantido o reconhecimento de suas especificidades e não tem garantido um aparato legal que fundamente a oferta de uma educação nos espaços escolares ou não que possibilite a sua emancipação, a luta contra a violência, que respeite as suas diferenças e suas demandas. Diante disso, vamos tentar compreender como os estados estão ou não preparados para essa leitura de uma educação que atenda ao que a V Confintea nos chama a operacionalizar na educação para a igualdade e equidade de gêneros.

A elaboração dos planos estaduais de educação em prisões decorreu da aprovação pelos Ministérios da Educação e da Justiça de diretrizes com vistas à ampliação e ao aprimoramento da oferta de educação em prisões. Por isso, é pertinente compreender como estes documentos abordam os direitos da população carcerária e, especificamente, os das mulheres privadas de liberdade.

$\mathrm{Na}$ criação das condições necessárias ao planejamento da educação em prisões nos estados, destacam-se três documentos legais: a Resolução 3/2009 do Conselho Nacional de Política Criminal e Penitenciária ${ }^{5}$, a Resolução 2/2010 do Conselho Nacional de Educação e o Decreto Presidencial n.7626 de 24 de novembro de 2011, que instituiu o Plano Estratégico de Educação no Âmbito do Sistema Prisional. Este documento definiu diretrizes, objetivos e competências do Ministério da Educação e do Ministério da Justiça para ampliar e aprimorar a oferta de educação de jovens e adultos, educação profissional e educação superior no sistema prisional.

Para dar continuidade ao estabelecimento de metas e ações voltadas à garantia do direito à educação em estabelecimentos prisionais brasileiros, o Departamento Penitenciário Nacional - DEPEN criou o "Guia com orientações para subsidiar as unidades federativas para a elaboração do plano de educação nas prisões" (DEPEN, s.d.).

\section{Impasses e desafios nos planos estaduais de educação em prisões}

A elaboração dos planos estaduais de educação em prisões ora analisados contou com o apoio do Departamento Penitenciário Nacional, que elaborou um guia para orientar o debate, o planejamento e a redação destes planos

\footnotetext{
${ }^{5}$ Regulamenta a estada, permanência e posterior encaminhamento das(os) filhas(os) das mulheres encarceradas.
} 
em cada estado. A recomendação era de ampliar essa construção aos diversos atores envolvidos na oferta da educação em prisões: educadores, gestores municipais e do estado, pesquisadores de instituições de ensino superior e outros. Desse modo, obter-se-ia uma visão ampliada das dificuldades de trabalho, bem como de demandas, impasses, desafios e possibilidades de ampliar e diversificar a oferta de educação de jovens e adultos em estabelecimentos prisionais, contemplando: a educação formal, voltada à elevação de escolaridade; a educação não formal, voltada para atividades artísticas, culturais, de lazer, qualificação profissional, inclusão digital e outras; e formação continuada, voltada à aprendizagem de agentes, técnicos, educadores e demais profissionais que atuam no sistema prisional.

No guia de orientação para subsidiar a elaboração dos planos estaduais de educação em prisões, constam os dados indispensáveis, os aspectos considerados relevantes para guiar a reflexão dos atores envolvidos neste planejamento. Dentre os diversos itens do documento, destacamos o intitulado "diagnóstico".

No "diagnóstico", o guia apresenta tabelas para levantamento da população carcerária, número de estabelecimentos prisionais, nível educacional dos presos, relação entre oferta educacional, demanda e outros. Nenhuma tabela, entretanto, solicita dados sobre a população carcerária feminina. A única tabela que dá indicações sobre as mulheres é a tabela 3 sobre "crianças em companhia das mães nos estabelecimentos femininos", o que não contribui efetivamente para conhecer o número de mulheres presas.

Alguns estabelecimentos, chamados "Presídio Feminino", permitem calcular o número de apenadas. Contudo, sabemos que ainda existem unidades com alas femininas - apesar de todas as orientações para a extinção de unidades prisionais mistas -, e estas não foi possível serem identificadas pelo levantamento. Esta é, portanto, a primeira indicação de que o mapeamento da população carcerária mantém as mulheres subsumidas em dados quantitativos aparentemente sem gênero.

Mais adiante, o guia apresenta orientações sobre a organização da educação formal. Neste capítulo do documento, o destaque às mulheres consta em um dos treze itens: "g) estratégias para garantir a educação formal nos estabelecimentos femininos". Algo semelhante acontece no capítulo intitulado "organização da educação não formal”, em que somente um dos sete itens diz respeito às mulheres especificamente: “d) estratégias para garantir a oferta de educação não formal nos estabelecimentos femininos". 
A pouca visibilidade das mulheres no guia de orientações para elaboração dos planos estaduais de educação em prisões agrava-se nos planos estaduais. A leitura destes documentos evidencia que os poucos itens do guia que se referem às ações voltadas à garantia do direito à educação das mulheres privadas de liberdade desaparecem no planejamento dos estados. As ações previstas para ampliar a oferta de educação formal e de educação não formal nos estabelecimentos prisionais são gerais, para todos os presídios, sem observar necessidades específicas das mulheres privadas de liberdade.

Outro aspecto que se destaca a partir da leitura dos planos estaduais é preocupante não apenas em relação ao atendimento educacional de mulheres, mas também dos homens. Nos dezoito estados analisados, o diagnóstico indicava que, em 2012, ano de elaboração dos planos, a oferta de educação formal estava muito aquém da demanda potencial da população carcerária.

Contudo, não sabemos o quanto esta defasagem atinge as mulheres. Este dado seria muito importante para estabelecer metas de reparação e equalização do direito à educação entre homens e mulheres, em consonância com as diretrizes curriculares da Educação de Jovens e Adultos, apresentadas no Parecer n.11 de 2000, do Conselho Nacional de Educação.

Conforme o relator Jamil Cury, a história da educação de jovens e adultos no Brasil é marcada pelas desigualdades sociais que atingem determinados grupos, dentre os quais destacamos as mulheres das classes populares. A abordagem da interseccional de gênero, raça e classe, elaborada por Kimberlé Crenshaw, nos Estados Unidos, ou de consubstancialidade, formulada por Daniele Kergoat, na França (HIRATA, 2018) são indispensáveis para compreender como as mulheres das classes populares no Brasil foram sobremaneira atingidas pela violação do direito à educação no Brasil.

Em estudo anterior (GODINHO, NOGUEIRA, BRANDÃO, 2017), ressaltamos a necessidade de que a Educação de Jovens e Adultos torne-se um espaço de reflexão coletiva, de problematização e de valorização das experiências de vida e de trabalho das mulheres, como modo de contribuir para que se reconheçam como sujeitos da educação e como sujeitos de direitos nesta sociedade desigual e meritocrática, que culpabiliza o indivíduo por suas próprias condições de pobreza, desemprego e baixa escolaridade.

Se considerarmos a Educação de Jovens e Adultos em contextos de privação de liberdade, este compromisso é ainda maior, pois para muitas destas mulheres a prisão representa o principal - ou mesmo o primeiro - acesso a uma política pública. Ou seja, a prisão é a primeira ação efetiva do Estado a que 
muitas das mulheres das classes populares têm acesso. Mesmo assim, elas não são alvo de ações específicas de elevação de escolaridade.

O planejamento dos estados ignorou também o item $\mathrm{D}$ da organização de educação não formal nos presídios femininos. O que consta nos planos analisados são ações previstas para o público em geral. Embora a educação não formal possa abranger atividades artísticas, culturais, esportivas, projetos de leitura, além de cursos, oficinas e projetos de qualificação profissional e de geração de renda, os planos não contemplam esta variedade de atividades.

Esse dado sinaliza uma desvalorização das atividades de educação não formal no sistema prisional. Contudo, esse tipo de atividades tem grande valor para a ampliação do acesso a temas e a processos educativos que atendam diretamente a interesses e necessidades específicos de cada grupo cultural que compõe a população prisional.

A esse respeito, Rangel (2006, p. 61) afirma que:

A educação não-formal é particularmente importante nesse sentido, uma vez que, por força de sua flexibilidade, oferece maiores opções para os presos. Em resumo, a educação em prisões deve estar voltada para fortalecer as práticas e as instituições democráticas, e contribuir para a formação cidadã.

Em consonância com a reflexão do autor, consideramos que uma das potências da educação não formal é que, por sua flexibilidade, ela tem condições de desenvolver processos educativos adequados à diversidade cultural do público da EJA que também se manifesta entre os/as estudantes em privação de liberdade. Seria equivocado pensar neste público como um todo homogêneo.

Apesar destas possibilidades de trabalho oferecidas pela educação não formal, os planos estaduais analisados não a priorizam na educação em prisões. Dos dezoito documentos analisados, três não apresentam nenhum tipo de oferta de educação não formal; sete limitam a oferta a cursos de qualificação profissional e, no máximo, mais um tipo de oferta (considerando que alguns estados mencionaram cultos e leitura da bíblia como atividade educativa não formal); e oito estados mencionam a oferta de três ou mais tipos de atividades educativas não formais. 


\section{Considerações Finais}

Nesse texto pretendemos problematizar a relação entre a normativa sobre a educação para as mulheres privadas de liberdade e a efetivação desse direito a partir de um olhar crítico sobre os planos estaduais para educação nas prisões publicados em 2012.

O debate sobre mulheres presas começa a ganhar evidencia no momento em que o número de encarceramento aumenta substancialmente. Como vimos, em dezesseis anos tivemos no Brasil um aumento de 656\% no número de mulheres encarceradas e passamos a ocupar o terceiro lugar em países que mais aprisionam mulheres.

Alguns normativos já mencionados caminham no sentido de garantir os direitos humanos para essas mulheres e ainda possibilita novos olhares sobre a prisão e as especificidades desses sujeitos, com a intencionalidade de construção de novas formas de operacionalização para atender a demanda crescente de mulheres presas.

Entre esses direitos a serem garantidos e reconhecidos a partir das especificidades das mulheres está o direito à educação, instituído por diferentes códigos normativos, como a Constituição Federal do Brasil de 1988. A partir disso, fomos buscar nos planos estaduais de educação nas prisões a operacionalização das normatizações, ou melhor, como os estados da federação estão encaminhando e efetivando esse direito?

Por que ao longo desse texto buscamos debater o direito à educação? Porque concordamos com Scarfó (2009, p. 111) que reconhece a educação como um direito humano que ao ser garantido "reduz a situação de vulnerabilidade social, cultural e emocional da pessoa privada de liberdade”, e como já dis cutimos, a mulher encarcerada está em vulnerabilidade social, portanto, a educação pode ser um dos caminhos na superação dessa situação. No entanto, constatamos a invisibilidade das mulheres em privação de liberdade nos diferentes documentos normativos. O mesmo ocorreu nos planos estaduais de educação nas prisões e - mais grave - a baixa oferta de educação nas prisões não é um problema que se restrinja aos presídios femininos: de modo geral, nem unidades femininas nem masculinas atendem a demanda. Pouco mais de $10 \%$ das pessoas privadas de liberdade exercem algum tipo de atividade educacional (BRASIL, 2016), embora 80\% aproximadamente da população prisional brasileira não tenha a escolaridade básica completa, isto é, o Ensino Médio comple- 
to. Estes dados sinalizam a gravidade da violação do direito à educação no sistema prisional do país.

Ainda precisamos avançar em termos normativos e operacionais na garantia do direito à educação e ao reconhecimento da especificidade das mulheres em privação de liberdade. Esperamos contribuir com esse texto no sentido de subsidiar novas pesquisas que avancem no debate da educação para mulheres presas e na avaliação das metas e encaminhamentos dos planos estaduais para educação nas prisões.

\section{Referências}

ALERJ (Assembleia Legislativa do Estado do Rio de Janeiro). Relatório Temático: mulheres, meninas e privação de liberdade. Rio de Janeiro: ALERJ, 2016.

BRASIL. Lei n. ${ }^{0}$ 7.210, de 11 de julho de 1984. Institui a Lei de Execução Penal. Diário Oficial da União, Brasília, DF, 13 jul. 1984. Disponível em: <http://www.planalto.gov.br/ccivil_03/leis/17210.htm>. Acesso em: 27 ago 2018.

. Constituição (1988). Constituição da República Federativa do Brasil. Brasília, DF: Senado, 1988.

. CONSELHO NACIONAL DE POLÍTICA CRIMINAL E PENITENCIÁRIA. Resolução n.3 de $\mathbf{1 1}$ de março de 2009. Brasília: CNPCP, 2009.

\section{. CONSELHO NACIONAL DE EDUCAÇÃO (CNE). Resolução}

CNE/CEB n. 2, de 2010. Dispõe sobre as Diretrizes Nacionais para a oferta de educação para jovens e adultos em situação de privação de liberdade nos estabelecimentos penais. Brasília, DF: CNE, 2010.

. Portaria Interministerial n. 210, de 16 de janeiro de 2014. Institui a Política Nacional de Atenção às Mulheres em Situação de Privação de Liberdade e Egressas do Sistema Prisional e dá outras providências. Diário Oficial da União, Brasília, DF, 17 jan. 2014. Seção 1, p. 75.

. Lei 13.005, de 25 de junho de 2014. Aprova o Plano Nacional de

Educação - PNE e dá outras providências. Diário Oficial da União, Brasília, DF, 26 jun. 2014. Seção 1, p. 1. 
. Ministério da Justiça. Departamento Penitenciário Nacional. Levantamento Nacional de Informações Penitenciárias Infopen Mulheres. Brasília, DF, 2016.

Regras de Mandela: Regras mínimas das Nações Unidas para o tratamento de presos. Brasília: Conselho Nacional de Justiça, 2016a.

Regras de Bangkok: Regras das Nações Unidas para o tratamento de mulheres presas e medidas não privativas de liberdade para mulheres infratoras. Brasília: Conselho Nacional de Justiça, 2016b

. DEPEN/MJ. Guia com orientações para subsidiar a elaboração do plano estadual de educação nas prisões. Brasília: DEPEN/MJ, s.d. FOUCAULT, M. Vigiar e Punir: nascimento da prisão. Petrópolis: Vozes, 2002.

FRANÇA, M. H. O. Criminalidade e prisão feminina: uma análise da questão de gênero. Revista Ártemis, v. XVIII, n. 1 ,p. 212-227, 2014.

GODINHO, A. C.F.; BRANDÃO, N. A.; NORONHA, A.C.M.N. Contribuições do pensamento freireano para a escolarização de mulheres trabalhadoras na Educação de Jovens e Adultos. Revista Inter-Ação, Goiânia, v. 42, n. 1, p. 20-37, jan./abr. 2017.

GOFFMAN, E. Manicômios, prisões e conventos. São Paulo: Editora Perspectiva, 1999.

HIRATA, H. Gênero, Patriarcado, Trabalho, Classe. Trabalho Necessário, Niterói, ano 16, n. 29, p. 14-27, 2018.

GUATTARI, F. Caosmose: um novo paradigma estético. São Paulo: Ed. 34, 1986.

ILGENFRITZ, I. Direito ou Punição? Representação da sexualidade feminina no Direito Penal. Porto Alegre: Editora Movimento, 2009.

KOLKER, T. Tortura nas prisões e produção de subjetividade. In: RAUTER, R.; PASSOS, E.; BENEVIDES, R.; (Org.). Clínica e política. Subjetividade e violação dos direitos humanos. Rio de Janeiro: Equipe Clínico-Grupal, Grupo Tortura Nunca Mais. Rio de Janeiro: Instituto Franco Basaglia/Editora Te Corá, 2002. p. 89 - 99.

JULIÃO, E. A ressocialização por meio do estudo e do trabalho no sistema penitenciário brasileiro. Em Aberto, v. 24, n. 86 ,p. 143-157, 2011. 
ONU. Regras Mínimas para o Tratamento dos Reclusos. Adotadas pelo Primeiro Congresso das Nações Unidas sobre a Prevenção do Crime e o Tratamento dos Delinqüentes, realizado em Genebra em 1955, e aprovadas pelo Conselho Econômico e Social das Nações Unidas através das suas resoluções 663 C (XXIV), de 31 de Julho de 1957 e 2076 (LXII), de 13 de Maio de 1977.Resolução 663 C (XXIV) do Conselho Econômico e Social.

RANGEL, H. Perspectiva Comparada de Práticas Educativas: Síntese para Vincular a Educação e a Justiça. In: UNESCO. Educando para a Liberdade. Brasília, 2006. p. 59-70

SCARFÓ, F. A educação pública em prisões na América Latina: garantia de uma igualdade substantiva. In: Educação em Prisões na América Latina: direito, liberdade e cidadania. Brasília: UNESCO, 2009. p. 107-137. 